\title{
A VISUALIZAC̣ÃO DE IMAGENS MÉDICAS SOB A PERSPECTIVA DA USABILIDADE MÓVEL
}

\author{
The visualization of medical images from the perspective of mobile \\ usability
}

\section{SCHMITT, Luciano Ernesto Arnold}

Universidade Federal de Santa Catarina - UFSC

lucianoarnold@gmail.com

\section{TRISKA, Ricardo}

Universidade Federal de Santa Catarina - UFSC

ricardo.triska@gmail.com

\section{GONÇALVES, Berenice Santos}

Universidade Federal de Santa Catarina - UFSC berenice@cce.ufsc.br

\section{Resumo \\ O uso de dispositivos móveis ganhou \\ Abstract} popularidade entre os profissionais da área da saúde e destaca-se, sobretudo, nos casos em que o acesso imediato e remoto a exames do paciente pode ser, muitas vezes, decisivo. Este artigo é fruto de um estudo que objetivou evidenciar as boas práticas em ergonomia e usabilidade móvel. Para tal, realizou-se a análise qualitativa de um aplicativo web para visualização de imagens médicas com base nas recomendações ergonômicas para projetos de interação móvel.

Palavras-chave: Ergonomia. Usabilidade. Mobilidade. Imagens médicas.

The use of mobile devices has gained popularity among professionals in the healthcare and stands out, especially in cases where the immediate and remote access to patient exams can often be decisive. This article is the result of a study that aimed to highlight best practices in ergonomics and mobile usability. For this, we carried out a qualitative analysis of $a$ web application for viewing medical images based on ergonomic recommendations for mobile interaction.

Keywords: Ergonomics. Usability. Mobility. Medical images. 


\section{INTRODUCূ̃̃O}

As tecnologias de informação e comunicação (TICs) estão presentes nos mais diversos momentos da vida do ser humano e, gradativamente, vêm influindo no modo com as pessoas realizam suas tarefas diárias, comunicam-se e interagem umas com as outras.

Diante da quantidade de recursos hoje disponíveis em computadores, tablets e smartphones, praticamente não existem mais barreiras para o acesso a informações e serviços. Neste contexto, novas possibilidades de ferramentas surgem em diversas áreas, incluindo a área da saúde.

O uso de dispositivos móveis ganhou popularidade entre os profissionais dessa área e destaca-se, sobretudo, nos casos em que o acesso imediato e remoto a exames ou informações do paciente pode ser, muitas vezes, decisivo.

A área que se ocupa em projetar sistemas interativos que forneçam suporte às atividades desenvolvidas pelo ser humano, considerando critérios ergonômicos e de usabilidade, denomina-se design de interação. (PREECE; ROGERS; SHARP, 2005). Segundo as autoras, os dispositivos móveis promovem o surgimento de um novo cenário a ser considerado dentro do design de interação: a interação móvel.

$\mathrm{Na}$ interação móvel, o modo como as pessoas se relacionam com os sistemas interativos é diferente da interação que ocorre por meio de um computador desktop - consequentemente, a experiência vivenciada por estes usuários também é peculiar.

A partir deste contexto, o presente trabalho objetivou um estudo do $X$ Viewer - aplicativo web para visualização de imagens médicas, desenvolvido pela empresa brasileira Pixeon S/A. A análise realizada teve caráter qualitativo/ descritivo e efetivou-se a partir de um processo orientado pelas recomendações ergonômicas apresentadas por Cybis; Betiol e Faust (2010): adequação ao contexto do usuário móvel; interface miniaturizada; consistência interna e externa; minimização de custo e carga de trabalho; facilidade de navegação; apoio à seleção de opções; cuidado com a rolagem da tela; apoio às interrupções e à personalização da interface.

\section{USABILIDADE E EXPERIÊNCIA DO USUÁRIO NO CONTEXTO DA INTERAC̣ÃO MÓVEL}

Segundo definição da ISO 9241-11 (INTERNATIONAL STANDARD ORGANIZATION, 2010) usabilidade refere-se ao atributo de um sistema interativo ao ser utilizado com eficácia, eficiência e satisfação por usuários 
específicos em um determinado contexto de uso. A eficácia é definida pelo efetivo cumprimento da tarefa; a eficiência pelos recursos e esforços gastos; e a satisfação pela qualidade da experiência do usuário durante a realização da tarefa.

De acordo com Preece, Rogers e Sharp (2005), o campo que se ocupa em projetar sistemas interativos que forneçam suporte às atividades desenvolvidas pelo ser humano, considerando critérios ergonômicos e de usabilidade, denomina-se design de interação.

Em virtude dos avanços científicos e tecnológicos verificados nas últimas décadas e com a popularização do uso de dispositivos móveis, observa-se uma mudança de paradigma no modo como as pessoas realizam suas tarefas diárias, comunicam-se e interagem umas com as outras, trazendo, segundo Cybis, Betiol e Faust (2010), um novo cenário a ser considerado dentro do design de interação: a interação móvel.

Na interação móvel, o modo como as pessoas se relacionam com os sistemas interativos é diferente da interação que ocorre por meio de um computador desktop - consequentemente, a experiência vivenciada por estes usuários também é peculiar. Hiltunen, Laukka e Luomala (2002) apresentam um conjunto de cinco fatores responsáveis por determinar a experiência do usuário móvel: utilidade, usabilidade, disponibilidade, estética e processo offline (Figura 1).

Figura 1 - Componentes da experiência do usuário móvel

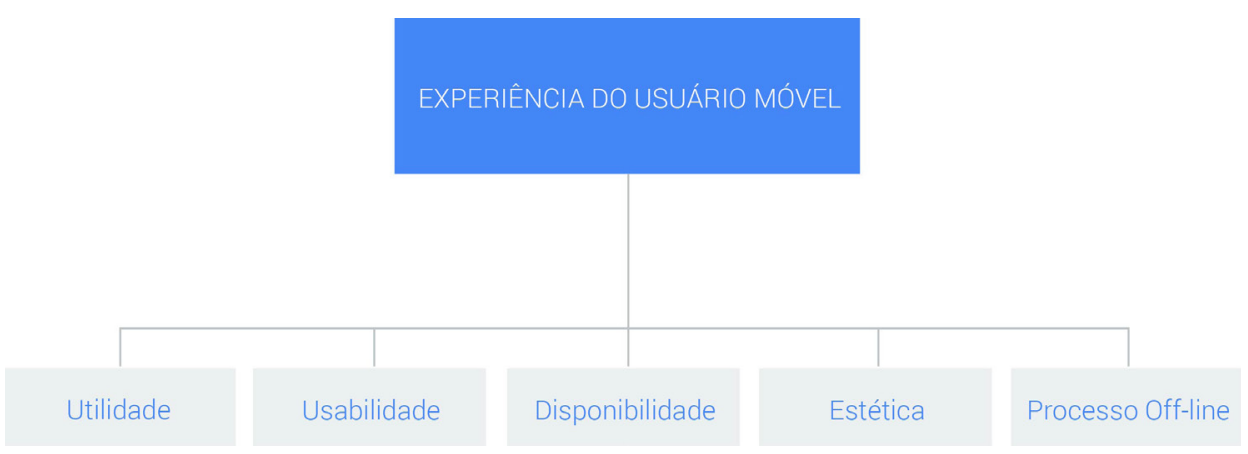

Fonte: Hiltunen, Laukka e Luomala (2002).

Utilidade: o serviço deve oferecer ao usuário vantagens que agreguem valor de uso dentro de um determinado contexto. Por exemplo: um médico está viajando e, em caráter emergencial, necessita acessar exames ou informações de um paciente. Neste caso, uma aplicação móvel revelaria a sua utilidade; 
Usabilidade: refere-se à norma ISO 9241:11 (INTERNATIONAL STANDARD ORGANIZATION, 2010), no que diz respeito à eficácia, eficiência e satisfação presentes na relação entre o usuário e o sistema interativo. No caso do médico, a usabilidade é um fator determinante para o cumprimento da tarefa em tempo hábil, com segurança e sem esforço;

Disponibilidade do sistema: o sistema deve estar sempre online e funcionando corretamente. Entretanto, no caso do médico, supondo que durante a análise dos exames do paciente haja uma queda de conexão em virtude de fatores externos ao projeto de interação (por exemplo, ausência de sinal da operadora), o sistema deve apresentar feedback indicando a interrupção do sinal e, quando reestabelecido, o serviço deverá retornar ao ponto exato de onde parou sem que ocorra a perda de informações;

Estética: refere-se às qualidades da camada visual da aplicação, ao seu apelo estético e a sua atratividade para o usuário. No caso do médico, a interface deve ainda apresentar atributos visuais que se adequem aos mais diversos contextos, prevendo o uso tanto em ambientes com baixa iluminação quanto ambientes com iluminação extrema;

Processo offline: refere-se aos elementos que não estão diretamente relacionados ao projeto de interação, mas que influenciam na experiência do usuário. No caso do médico, por exemplo, a confiança no nome da empresa que oferece o serviço e a garantia de segurança e sigilo dos dados acessados é essencial para uma boa experiência.

Nielsen e Budiu (2012) afirmam que a experiência do usuário móvel varia também de acordo com a dimensão da tela do dispositivo - quanto maior a tela, melhor será a experiência. Neste contexto, destacam-se as telas sensíveis ao toque ocupando praticamente todo o dispositivo e a GUI (Graphical User Interface).

As telas sensíveis ao toque representam outro diferencial na interação por meio de computadores desktops e os dispositivos móveis: o canal utilizado para entrada de dados. Enquanto os primeiros utilizam basicamente mouse e teclado, os segundos utilizam o próprio dedo humano.

Segundo Saffer (2009), interações por meio de telas sensíveis ao toque configuram-se em movimentos físicos executados pelo ser humano sobre uma superfície sensível ao toque que são detectados através de sensores sem que haja a necessidade do uso de mouses, teclados ou canetas específicas.

Por fim, considerando as particularidades existentes entre uma aplicação 
móvel e uma aplicação desktop, Nilsen e Budiu (2012) afirmam que o desenvolvimento de cada uma delas requer projetos específicos, proporcionando assim a melhor experiência para o usuário de acordo com cada contexto de uso.

\section{PERSPECTIVAS EM SAÚDE MÓVEL NO BRASIL}

De acordo com Iwaia et al. (2014), a rápida expansão da cobertura móvel no Brasil e utilização de dispositivos móveis incentivou o surgimento de uma categoria de aplicativos chamada m-Saúde. Estes sistemas têm auxiliado no monitoramento, na avaliação e no gerenciamento do estado de saúde e bemestar da população brasileira. Os aplicativos m-Saúde dividem-se em duas categorias:

\section{Aplicativos de pesquisa e vigilância em saúde}

Utilizados por agentes comunitários de saúde (ACS) durante o recolhimento dos dados de uma população. Um exemplo deste tipo de aplicativo é o SIAB-Fácil (Figura 2), um sistema de informação de atenção básica da saúde da família (IWAIA et al., 2014).

Figura 2 - SIAB-Fácil

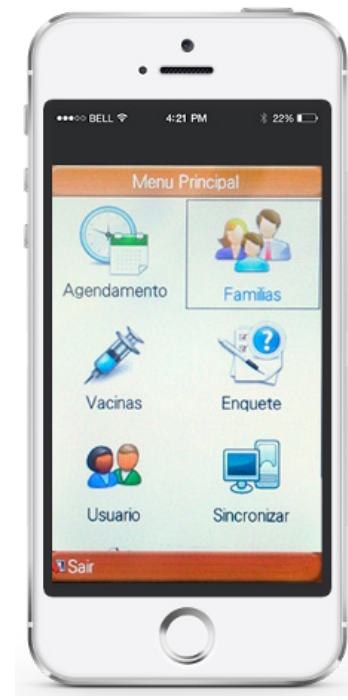

Fonte: PR Sistemas (2014).

\section{Aplicativos de registros dos pacientes}

Utilizados principalmente por médicos, estes aplicativos funcionam como prontuários eletrônicos para o registro, armazenamento e acesso de dados clínicos dos pacientes. O ClinicWeb (Figura 3) é um exemplo desta categoria de aplicativo m-Saúde. Ele foi desenvolvido pela Universidade Federal de São Paulo e está sendo utilizado atualmente pelo seu departamento de saúde (MARTA et al., 2010 apud IWAIA et al., 2014). 
Figura 3 - ClinicWeb
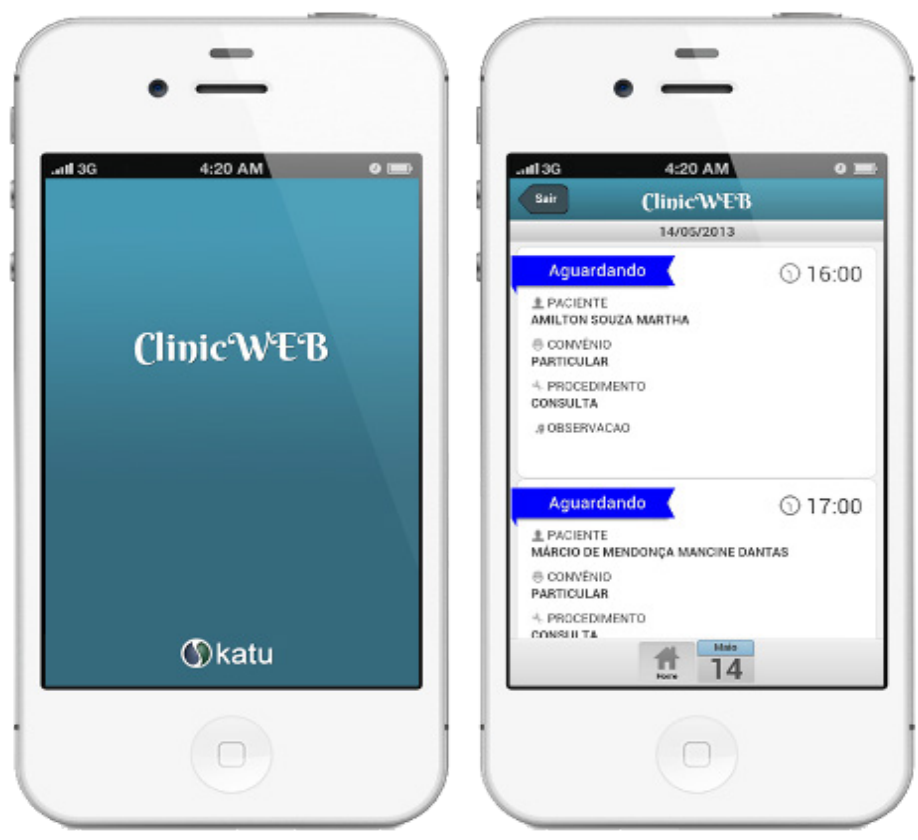

Fonte: KATU (2014).

De acordo com Marin (2013), embora muitos aplicativos para a área de saúde estejam disponíveis, nota-se ainda pouca exploração de recursos e funcionalidades. A maioria deles não possui integração com registros eletrônicos e alguns requisitos exigidos na área médica como proteção, confidencialidade, segurança e privacidade da informação nem sempre são verificados.

\section{CARACTERIZAC̣̃̃O DO ESTUDO}

\section{Tipo de Estudo}

O estudo proposto possui um caráter qualitativo e descritivo, efetivado a partir de um processo de análise orientada pelas recomendações ergonômicas apresentadas por Cybis, Betiol e Faust (2010). Esta modalidade de estudo não exige o envolvimento do usuário e sua aplicação é normalmente conduzida por projetistas ou especialistas em usabilidade.

\section{Objeto de Análise}

O objeto de análise é o XViewer (Figura 4) - um aplicativo web para visualização de imagens médicas. Ele é de domínio da empresa brasileira Pixeon $\mathrm{S} / \mathrm{A}$ e seu uso é restrito.

O XViewer não requer qualquer tipo de instalação. Seu acesso é via web e ele apresenta compatibilidade com os principais navegadores do mercado: Chrome, Firefox, Safari, Android, iOS e Internet Explorer. O aplicativo conta ainda com versões específicas para uso em desktops, tablets e smartphones. 
Figura 4 - XViewer

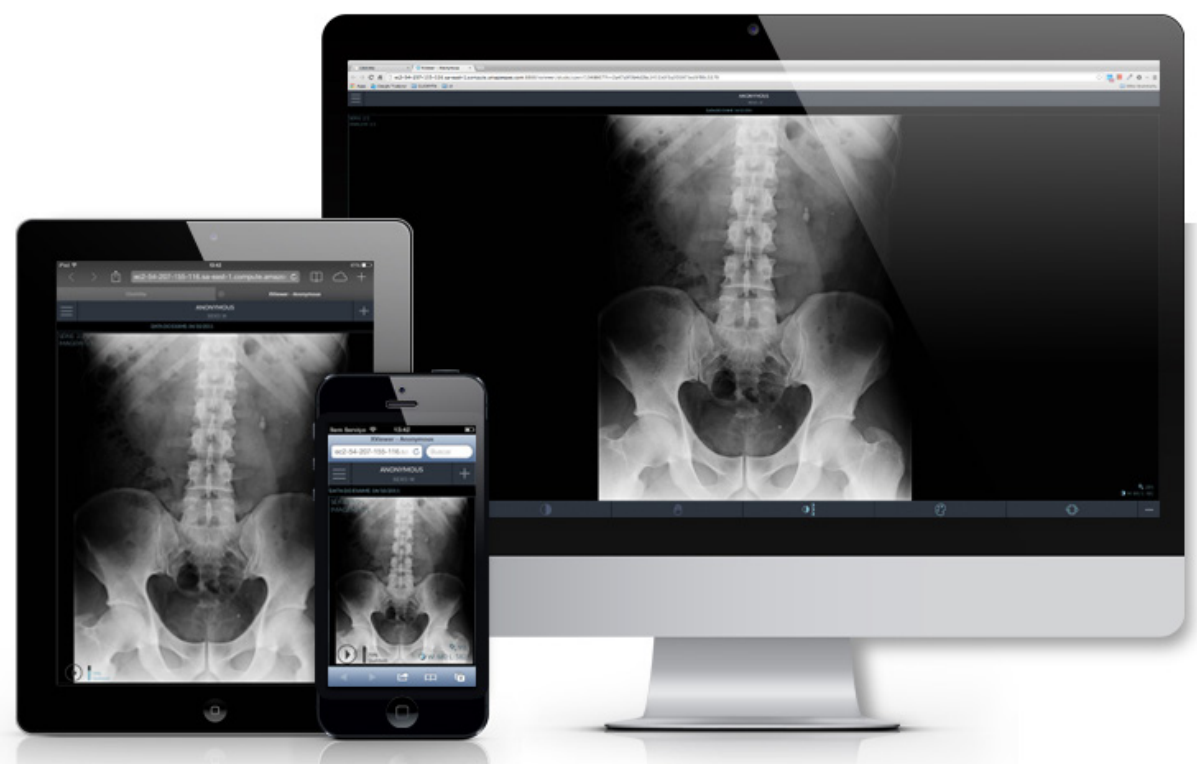

Fonte: Os autores

\section{Método e Critérios Adotados}

O estudo baseou-se nas recomendações ergonômicas para projetos de interação móvel propostas por Cybis, Betiol e Faust (2010). São elas:

Adequação ao contexto do usuário móvel: oferecer alternativas que explorem a mobilidade do dispositivo e promovam soluções de acordo com o contexto e localização do usuário;

Interface miniaturizada: a interface deve ser projetada especialmente para visualização em dispositivos móveis, considerando aspectos como resolução e restrições físicas da tela;

Consistência interna e externa: além da consistência interna - ou seja, linguagem e padrões preservados em todas as telas do sistema - a interface deve ainda apresentar elementos comumente utilizados em outras plataformas e já incorporados ao repertório do usuário;

Minimização de custo e carga de trabalho: reduzir o número de cliques e de telas para as tarefas executadas com maior frequência, bem como utilizar atalhos e ícones que facilitem a memorização e reduzam a carga cognitiva do usuário;

Facilidade de navegação: evitar os menus profundos e submenus, dando preferência aos menus rasos e sempre oferecer ao usuário a possibilidade de retornar à página anterior ou ao menu principal; 
Apoio à seleção de opções: sempre que possível, deve-se fornecer mecanismos de seleção (por exemplo, links e ícones), ao invés de solicitar que o usuário insira comandos ou informações manualmente;

Cuidado com a rolagem da tela: as rolagens de tela não devem ser utilizadas em excesso, uma vez que, quanto maior a rolagem, proporcional é a quantidade de informações que o usuário terá de armazenar em sua memória para que as informações que ele não está mais vendo possam lhe fazer sentido diante do que está sendo exibido atualmente;

Apoio às interrupções: caso ocorra queda de conexão ou de energia, o sistema deve armazenar dados que permitam ao usuário posteriormente retornar ao ponto exato em que houve a interrupção sem que haja perda de informações ou necessidade de repetir a entrada de comandos já efetuados;

Apoio à personalização da interface: o sistema deve permitir a personalização da interface de acordo com as necessidades, preferências e/ ou restrições de cada usuário em determinado contexto de uso, considerando fatores como, por exemplo, a iluminação do ambiente.

Vale esclarecer que apesar de objeto de análise - o aplicativo XViewer estar disponível para acesso via desktops, tablets e smartphones, o foco deste estudo é a interação móvel, portanto a apreciação ergonômica irá considerar apenas o uso do aplicativo em dispositivos móveis.

\section{RESULTADOS}

\section{Adequação ao Contexto do Usuário Móvel}

$O$ atendimento a este critério é o princípio básico do XViewer. $O$ aplicativo revela a sua utilidade, sobretudo, nos casos em que o médico necessita, em caráter emergencial, acessar remotamente as imagens médicas de um paciente. Vale lembrar que, uma vez que o exame é de propriedade do paciente, ele também possui acesso a estas imagens e pode compartilhá-las via internet com outros médicos para, por exemplo, obter uma segunda opinião a respeito do seu diagnóstico.

\section{Interface Miniaturizada}

O XViewer possui versões específicas para o uso em desktops e dispositivos móveis, característica esta que evidencia a preocupação com a experiência do usuário de acordo com o contexto de uso. Ao utilizar o aplicativo em um tablet e em um smartphone (Figura 5) constatou-se aquilo que Nielsen e Budiu (2012) falam a respeito das dimensões da tela: quanto maior a tela, melhor será a experiência. Por se tratar de um visualizador de imagens acredita-se que, no caso do XViewer, uma dimensão razoável de tela seja fator preponderante 
para que critérios ergonômicos e de usabilidade sejam atendidos com maior competência.

Figura 5 - Visualização do XViewer em tablet e smartphone

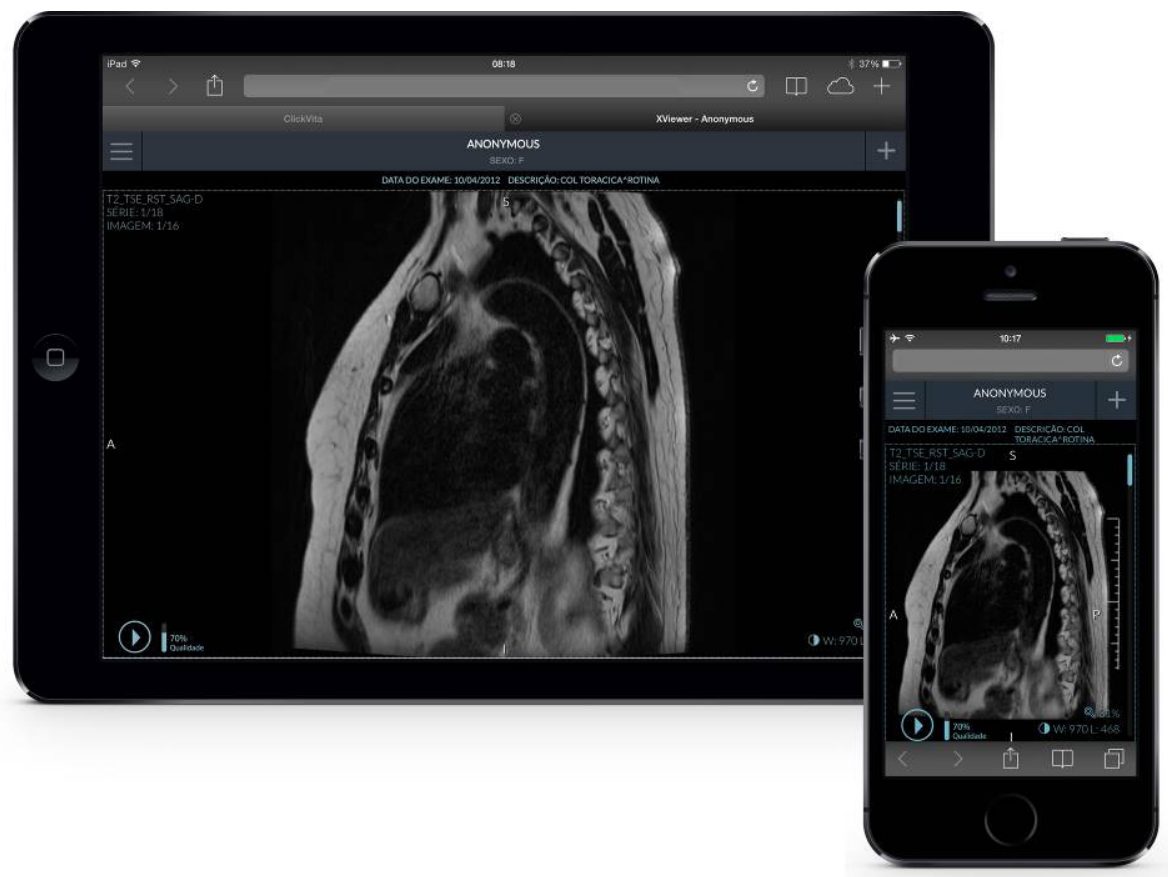

Fonte: Os autores.

\section{Consistência Interna e Externa}

No que se refere à consistência interna, o XViewer apresenta coerência na utilização de ícones, no posicionamento dos menus e na exploração de padrões cromáticos para representar os níveis de status dos componentes. Por exemplo, em toda a arquitetura do aplicativo, a cor cinza sinaliza a indisponibilidade ou desativação de um componente, enquanto a cor verde indica a sua disponibilidade ou ativação (Figura 6).

Em se tratando da consistência externa, os elementos anteriormente citados também apresentam conformidade com o que normalmente se encontra nesta categoria de aplicativos. Vale ressaltar, ainda, que as interações gestuais adotadas para efetuar a manipulação das imagens, seguem padrões já presentes no repertório dos usuários de dispositivos com telas sensíveis ao toque. Por exemplo, o movimento de pinça é utilizado para aplicar zoom (aproximar ou afastar a imagem) e o movimento de arraste rápido do dedo para o lado é utilizado para avançar para a próxima imagem do exame ou voltar para a anterior.

Figura 6 - Ícones das ferramentas do sistema 


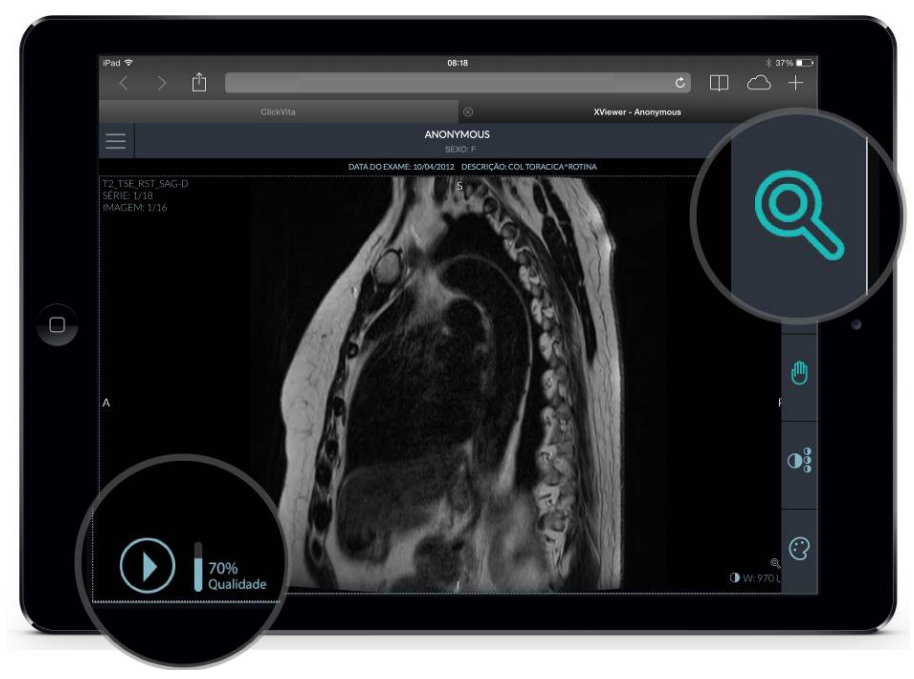

Fonte: os autores

\section{Minimização de Custo e Carga de Trabalho}

Todas as funcionalidades do XViewer estão disponíveis em dois menus de rápido acesso e são representadas por ícones de fácil reconhecimento por usuários desta categoria de aplicativo. Em relação aos padrões de interação gestual adotados pelo sistema, apesar de eles já fazerem parte do repertório dos usuários de aplicações móveis, o sistema poderia dispor de um tutorial para usuários menos experientes - a fim de minimizar a curva de aprendizado e, consequentemente, reduzir a carga cognitiva para estes usuários.

\section{Facillidade de Navegação}

O XViewer não possui menus profundos ou submenus. A navegação é facilitada por meio do acesso a dois menus simples localizados na barra superior (Figura 7). O menu à esquerda comporta a lista com as imagens do exame, a ferramenta de linhas de referência e as opções de layout para visualização do exame. Já no menu à direita encontram-se as ferramentas de manipulação e edição de imagem, tais como: zoom, janelamento, pan, janelamentos prédefinidos e paletas de cores. Vale destacar que os menus podem estar sempre visíveis ou recolhidos.

Figura 7 - Menus de navegação

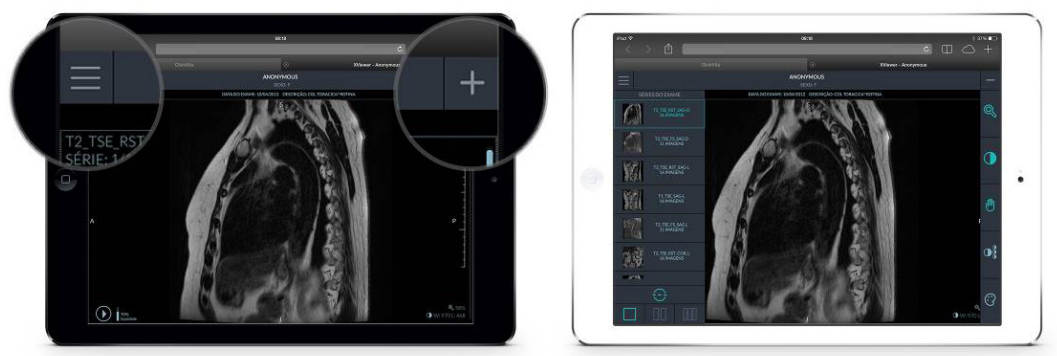

Fonte: Os autores 


\section{Apoio à Seleção de Opções}

Em apoio à execução de tarefas, o aplicativo possui um ícone para acesso a cada funcionalidade, evitando assim o uso de comandos que requeiram a inserção de dados textuais.

\section{Cuidado com a Rolagem da Tela}

No XViewer a barra de rolagem é utilizada apenas para efetuar a passagem das imagens do exame. Esta mesma operação pode ser realizada por meio de interação gestual sobre a superfície sensível ao toque (movimento de arraste rápido do dedo para o lado).

\section{Apoio às Interrupcões}

O aplicativo mantém os dados de acesso preservados no caso da perda de conexão com a internet ou queda de energia. Deste modo, quando reestabelecido o serviço, o usuário pode dar continuidade à execução das tarefas do ponto em que estava.

\section{Apoio à Personalização da lnterface}

O XViewer oferece três opções de layouts (Figura 8) para que o médico possa, por exemplo, efetuar comparações de imagens lado a lado. Além disso, o aplicativo dispõe de paletas de cores (Figura 9) que auxiliam a destacar determinadas estruturas anatômicas do paciente.

Figura 8 - Layouts de visualização
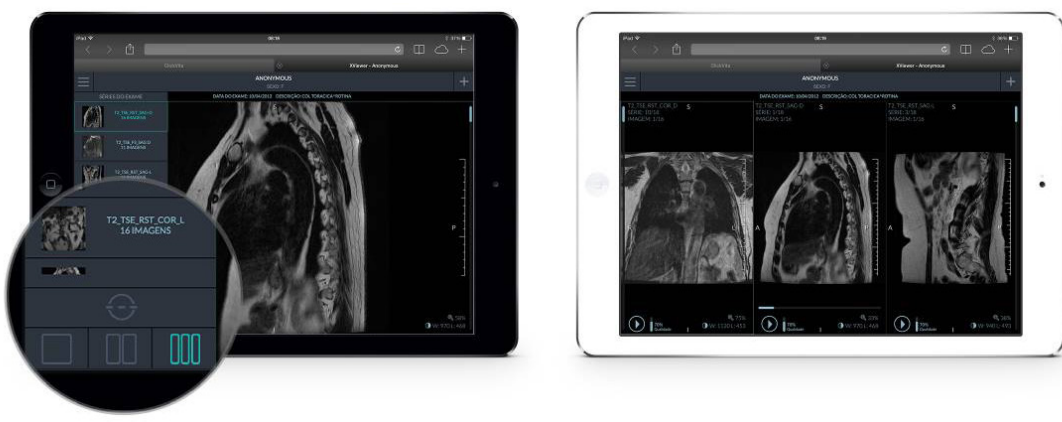

Fonte: Os autores.

Figura 9 - Paletas de cores
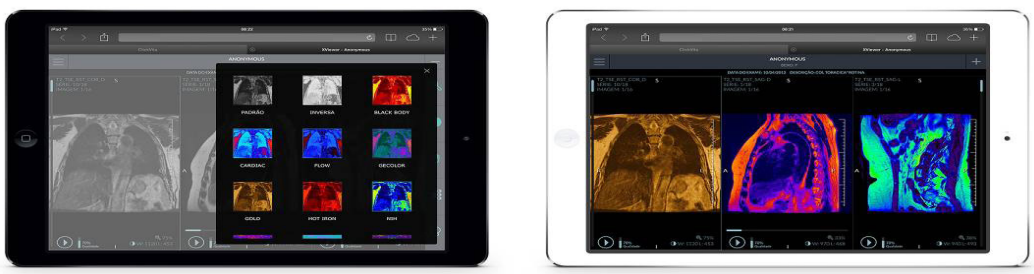
Fonte: Os autores

Não são oferecidas, entretanto, opções para a personalização das cores do plano de fundo do próprio aplicativo - prevendo, por exemplo, o seu uso em ambientes com diferentes níveis de iluminação.

Por fim, a Tabela 1 apresenta os critérios que foram abordados neste estudo e o nível de atendimento de tais critérios por parte do aplicativo objeto da análise.

Tabela 1 - Critérios abordados no estudo e nível de atendimento

\begin{tabular}{|l|c|c|c|}
\hline $\begin{array}{l}\text { Adequação ao contexto do } \\
\text { usuário móvel }\end{array}$ & Atende & $\begin{array}{c}\text { Atende } \\
\text { parcialmente }\end{array}$ & $\begin{array}{c}\text { Não } \\
\text { atende }\end{array}$ \\
\hline Interface miniaturizada & $X$ & & \\
\hline Consistência interna e externa & $X$ & & \\
\hline $\begin{array}{l}\text { Minimização de custo e carga } \\
\text { de trabalho }\end{array}$ & & & \\
\hline Facilidade de navegação & $X$ & & \\
\hline Apoio à seleção de opções & $X$ & & \\
\hline Cuidado com a rolagem da tela & $X$ & & \\
\hline $\begin{array}{l}\text { Apoio às interrupções e à per- } \\
\text { sonalização da interface }\end{array}$ & & & \\
\hline
\end{tabular}

Fonte: Os autores.

\section{CONSIDERAC̄ÕES FINAIS}

Este trabalho procurou evidenciar as boas práticas em ergonomia e usabilidade sob a perspectiva do usuário móvel. Para isto, realizou-se um estudo analítico do XViewer - aplicativo web para visualização de imagens médicas com base em recomendações ergonômicas para projetos de interação móvel.

Ao final do estudo, considerou-se que o aplicativo atende a praticamente todos os critérios estabelecidos e isto se deve, sobretudo, ao fato de ele possuir versões específicas para uso em plataformas desktop e mobile.

Não obstante, outras investigações poderiam ainda ser realizadas em estudos futuros - desta vez, considerando a utilização de métodos que envolvessem a participação de usuários do aplicativo em seu real contexto de uso. 


\section{REFERÊNCIAS}

CYBIS, Walter; BETIOL, Adriana; FAUST, Richard. Ergonomia e usabilidade: conhecimentos, métodos e aplicações. 2 ed. São Paulo: Novatec, 2010.

HILTUNEN, Mika; LAUKKA, Markku; LUOMALA, Jari. Mobile user experience. Finland: Edita Publishing Inc., 2002.

INTERNATIONAL STANDARD ORGANIZATION.ISO 9241 part 210: humancentred design for interactive systems. Genebra, 2010.

IWAIA, Leonardo; GOMES, Marco Aurélio Lins; SIMPLICIO JUNIOR, Marcos Antonio; CARVALHO, Tereza Cristina Melo de Brito; DOMINICINI, Cristina Klippel; SAKURAGUI, Rony Rogério Martins; NÄSLUND, Mats; HAKANSSON, Peter; REBELO, Marina; GUTIERREZ, Marco Antonio. Iniciativas em saúde móvel no Brasil. In: BARBOSA, Alexandre F. (Coord.). TIC saúde 2013. São Paulo: Comitê Gestor da Internet no Brasil, 2014. p. 75-86. Disponível em: $<$ http://cetic.br/publicacoes/2013/tic-saude-2013.pdf>. Acesso em: 15 jun. 2014.

KATU. Disponível em:<www.clinicweb.com.br>. Acesso em: 15 jun. 2014.

MARIN, Heimar. Tecnologia da informação e comunicação e a segurança do paciente. In: BARBOSA, Alexandre F. TIC Saúde 2013. São Paulo: Comitê Gestyor da Internet no Brasil, 2014. p. 67-74. Disponível em: <http://cetic.br/ publicacoes/2013/tic-saude-2013.pdf>. Acessado em: 15 jun. 2014.

NIELSEN, Jacob; BUDIU, Raluca. Mobile usability. Berkeley: New Riders, 2012.

PR SISTEMAS. SIAB fácil. Disponível em: < http://www.siabfacil.com.br/index. php>. Acesso em: 9 jun. 2014.

PREECE, Jennifer; ROGERS, Yvonne; SHARP, Helen. Design de interação: além da interação homem-computador. Porto Alegre: Brookman, 2005.

SAFFER, Dan. Designing gestural interfaces. Cambridge: O'Reilly, 2009. 


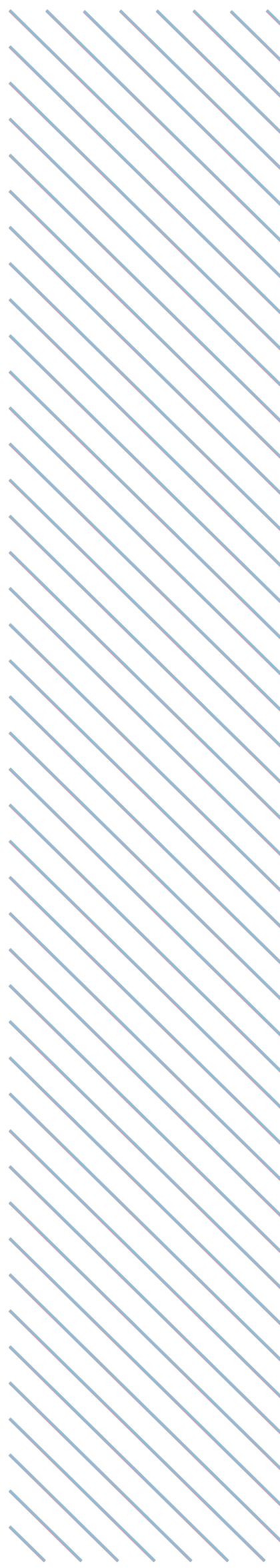

